\title{
PERAN GURU DALAM MEMBANGUN REPUTASI SEKOLAH MELALUI KOMUNIKASI ORGANISASI
}

\author{
Sinta Paramita ${ }^{1}$, Riris Loisa ${ }^{2}$, dan Yugih Setyanto ${ }^{3}$ \\ ${ }^{1}$ Prodi Ilmu Komunikasi, Universitas Tarumanagara \\ Surel: sintap@fikom.untar.ac.id \\ ${ }^{2}$ Prodi Ilmu Komunikasi, Universitas Tarumanagara \\ Surel: ririsl@fikom.untar.ac.id \\ ${ }^{3}$ Prodi Ilmu Komunikasi, Universitas Tarumanagara \\ Surel: yugihs@fikom.untar.ac.id
}

\begin{abstract}
Problems related to organizational communication climate have become common problems in various institutions. Cases related to conflict problems in multiple organizations occur at various levels, from organizations or institutions in a small scope to rice, including educational institutions such as schools. By creating an excellent organizational communication climate, educational services such as learning and others can make an image and reputation for the school. Seeing the portrait of the problem, the PKM Fikom Untar Team strives to help schools build a good reputation in organizational communication. The theme raised by the Fikom Untar PKM Team was "The Role of Teachers in Building School Reputation through Organizational Communication," which will be carried out at Lia Stephanie School, West Jakarta, which is considered to be able to help solve problems faced by schools. The method applied to solving this problem is to map the problem and provide the right solution. The activity held on August 15, 2019, was attended by school managers and all teachers. The results obtained from this activity, the participants know and understand the understanding of internal communication principles and how to build a corporate image and organizational culture elements. With increased awareness of organizational communication, it is hoped to create an excellent organizational communication climate. Community Service Activities carried out by the Faculty of Communication Sciences at Tarumanagara University are expected to be input for stakeholders in institutions, especially schools, to fix communication problems and maximize educational services.
\end{abstract}

Keywords: Organizational Communication, Reputation, Organizational Image

\begin{abstract}
ABSTRAK
Masalah terkait iklim komunikasi organisasi ternyata menjadi jamak masalah di berbagai lembaga. Kasus-kasus terkait masalah konflik dalam organisasi jamak terjadi di berbagai level baik organisasi atau institusi dalam cakupan kecil hingga beras termasuk institusi pendidikan seperti sekolah. Dengan menciptakan suasana iklim komunikasi organisasi yang baik, pelayanan pendidikan seperti pembelajaran dan lain-lain dapat menciptakan citra dan reputasi bagi sekolah tersebut. Melihat potret permasalahan tersebut Tim PKM Fikom Untar berupaya membantu sekolah dalam membangun reputasi yang baik dalam komunikasi organisasi. Tema yang diangkat oleh Tim PKM Fikom Untar adalah "Peran Guru Dalam Membangun Reputasi Sekolah Melalui Komunikasi Organisasi" yang akan dilakukan di Sekolah Lia Stephanie Jakarta Barat, dirasa dapat membantu dalam menyelesaikan masalah yang dihadapi sekolah. Metode yang diterapkan dalam menyelesaikan masalah ini adalah dengan melakukan pemetaan permasalahan dan memberikan solusi yang tepat. Kegiatan yang dilaksanakan pada tanggal 15 Agustus 2019, diikuti oleh pengelola sekolah dan seluruh guru. Hasil yang diperoleh dari kegiatan tersebut peserta mengetahui dan memahami terkait pemahaman asas komunikasi internal, cara membangun citra organisasi, dan elemen budaya organisasi, dengan meningkatnya pemahaman terkait komunikasi organisasi diharapkan dapat menciptakan iklim komunikasi organisasi yang baik. Kegiatan Pengabdian Kepada Masyarakat yang dilakukan Fakultas Ilmu Komunikasi Universitas Tarumanagara diharapkan dapat menjadi masukan bagi para pemangku kepentingan di dalam institusi khususnya sekolah untuk dapat memperbaiki masalah komunikasi dan memaksimalkan pelayanan pendidikan.
\end{abstract}

Kata Kunci: Komunikasi Organisasi, Reputasi, Citra Organisasi

\section{PENDAHULUAN}

Komunikasi merupakan suatu proses sosial dimana individu menggunakan simbol untuk membangun dan menginterpretasikan makna dalam lingkungan mereka, melalui unsur komunikasi termediasi dengan peran teknologi dalam masyarakat kontemporer (Turner, 2017). Lebih lanjut Tuner menekankan pada lima aspek yang penting dalam komunikasi yaitu: sosial, proses, simbol, makna, dan lingkungan. Dalam konteks organisasi, komunikasi dapat didefinisikan sebagai 
interaksi internal dan eksternal pada bagian unit-unit komunikasi dari suatu organisasi. Namun arti penting komunikasi organisasi yang telah didefinisikan oleh parah ahli belum merujuk kepada sebuah pemahaman bersama. Seperti pandangan Redding dan Sanborn menjelaskan komunikasi organisasi adalah pengiriman dan penerimaan informasi dalam organisasi yang kompleks. Sedangkan Katz dan Kahn berpandangan komunikasi merupakan pertukaran informasi dan pemindahan arti dari sebuah organisasi. Sebagai sebuah sistem yang terbuka yang menerima energi dari lingkungan dan mengubah energi menjadi produk atau servis dari sistem kepada lingkungan. Lebih lanjut Greenbaunm mendefinisikan komunikasi organisasi sebagai arus komunikasi internal dan eksternal dan memandang komunikasi pribadi sebagai tujuan organisasi (Muhammad, 2015).

Walaupun dari ketiga definisi dari para ahli komunikasi organisasi tidak sepaham, namun terdapat kesamaan terkait pengiriman dan penerimaan pesan sebagai landasan utama dalam komunikasi dalam sebuah organisasi. Komunikasi organisasi terbentuk dari proses pertukaran pesan antara unit komunikasi yang berada dalam suatu organisasi. Organisasi memiliki unit-unit komunikasi dalam hubungan yang saling berketerkaitan dalam lingkungan. Manusia terlibat sebagai subyek dalam proses menerima, menafsirkan, dan bertindak atas informasi. Komunikasi (Panuju \& Narena, 2019). Organisasi terbentuk diawali dari sebuah interaksi atau komunikasi antara individu yang memiliki tujuan bahwa mereka tengah berorganisasi (Morissan, 2009).

Dalam Proses Komunikasi organisasi, hambatan komunikasi jamak ditemui. Hambatan komunikasi dapat mengganggu proses mencapai tujuan dari sebuah organisasi seperti tidak tersampaikannya informasi yang benar pada semua unit dalam organisasi, konflik kepentingan, masalah komunikasi dengan berbagai macam budaya dalam sebuah organisasi, dan lain-lain. Penelitian ini memaparkan bahwa konflik yang tidak ditangani dengan baik akan menjalar lebih jauh hingga dapat menjatuhkan organisasi tersebut. Oleh sebab itu peran Public Relations sangat penting untuk memainkan perannya dalam keadaan krusial untuk membangun, mengembangkan, dan memelihara hubungan dan komunikasi antara perusahaan dengan publik. Penelitian yang telah dilakukan Redding menunjukkan bahwa iklim komunikasi lebih luas dari persepsi karyawan terhadap kualitas hubungan dan komunikasi dalam organisasi serta tingkat pengaruh dan keterlibatan. Lebih lanjut Redding juga memaparkan lima dimensi penting dari iklim komunikasi organisasi yaitu (Muhammad, 2015) seperti; Supportiveness, Partisipasi, Kepercayaan, Keterbukaan dan Keterusterangan, dan Tujuan kerja yang tinggi. Lebih lanjut Steve Kelneer menyebutkan enam dimensi iklim organisasi yaitu; Flexibility conformity, Responsibility, Standards, Reward, Clarity, dan Tema commitment. Dari pemaparan komunikasi organisasi di atas, dirasa penting organisasi membangun iklim organisasi yang sehat agar tercapai tujuan-tujuan dari organisasi tersebut. Secara langsung kegiatan tersebut dapat menciptakan citra dan reputasi sekolah kepada khalayak. Citra menurut Thomas L. Harris (dalam Wahid, 2017) adalah suatu proses "nothing" diupayakan menjadi "something" Dari yang tidak tahu menjadi tahu, setelah tahu menjadi suka, dan kemudian diharapkan timbul sesuatu (something) yaitu berupa citra. Sedangkan reputasi memeiliki empat acuan dalam sebuah institusi seperti yang dikatakan Adrianto (dalam Tamburian, 2015) yaitu; Credibility (Kredibilitas di mata para investor), Trustworthiness, Reliability (Keterandalan di mata konsumen), Responsibility (Tanggung jawab sosial).

Pada konteks di atas dibutuhkan seorang Public Relations untuk dapat membantu organisasi dalam proses mencapai tujuan. Public Relations sebagai jembatan penghubung dalam sebuah komunikasi antara perusahaan dengan masyarakat, diharapkan mampu menjadi jalan bagi keduanya. Dalam upaya membangun komunikasi maka diperlukan komunikasi dengan pendekatan budaya atau intercultural communication (Yayu, Anisti, Hidayat, \& Suhadi, 2019). Sekolah sebagai sebuah organisasi juga membutuhkan iklim komunikasi yang baik dalam proses pembelajaran dan pelayanannya. Dengan iklim komunikasi yang baik di sekolah antara yayasan, pengelola sekolah, 
siswa, orang tua, dan eksternal akan menciptakan siswa-siswa yang berkualitas. Namun masih ada beberapa sekolah yang mengalami masalah komunikasi oraganisasi, sehingga dapat menghambat tujuan-tujuan dari organisasi tersebut. Salah satunya adalah sekolah swasta Lia Stephanie yang terletak di Taman Surya Blok EE 2 No. 20-27 Pegadungan Kalideres Jakarta Barat. rumusan permasalahan yang dihadapi oleh mitra, yaitu; terdapat konflik yang terjadi pada lingkung sekolah dan tidak adanya hambatan komunikasi yang baik secara vertikal dan horizontal di lingkungan sekolah

Berdasarkan permasalahan mitra di atas untuk meningkatkan iklim komunikasi organisasi yang baik di Sekolah Lia Stephanie, maka Tim melakukan diskusi pengelola sekolah atau guru-guru yang ada di lingkungan sekolah Lia Stephanie. Hal tersebut akan dijadikan masukan untuk menemukan solusi yang tepat dari permasalahan tersebut. Jarak antara Sekolah Lia Stephanie dari Fakultas Ilmu Komunikasi Universitas Tarumanagara sebanyak $15.4 \mathrm{Km}$ ditunjukkan dengan bantuan peta google di bawah ini:

\section{METODE PELAKSANAAN}

Metode pelaksanaan yang digunakan dalam kegiatan ini meliputi beberapa langkah berikut ini:

1) Tim kegiatan pengabdian kepada masyarakat FIKOM Untar mendapat undangan Yayasan Lia Stephanie

2) Tim PKM Fikom Untar melakukan korespondensi dengan pihak Yayasan Lia Stephanie di Fikom Untar

3) Tim kegiatan pengabdian kepada masyarakat FIKOM Untar membuat proposal terkait kebutuhan mitra tersebut.

4) Pelaksanaan workshop Pemberdayaan Guru Dalam Membangun Komunikasi Organisasi Di SMA Lia Stephanie Jakarta Barat

5) Tahap penyusunan pelaporan kegiatan PKM terhadap tema Pemberdayaan Guru Dalam Membangun Komunikasi Organisasi Di SMA Lia Stephanie Jakarta Barat.

Secara terperinci kegiatan PKM ini akan dilaksanakan dalam beberapa tahap, yaitu pertama adalah tahap pra kegiatan yang meliputi audiensi dan diskusi dengan mitra; tahap kedua adalah pelaksanaan kegiatan; dan tahap terakhir adalah paska pelaksanaan kegiatan yang didalamnya meliputi luaran PKM dan monitoring serta evaluasi. Gambar 1 adalah tahapan kegiatan PKM ini.

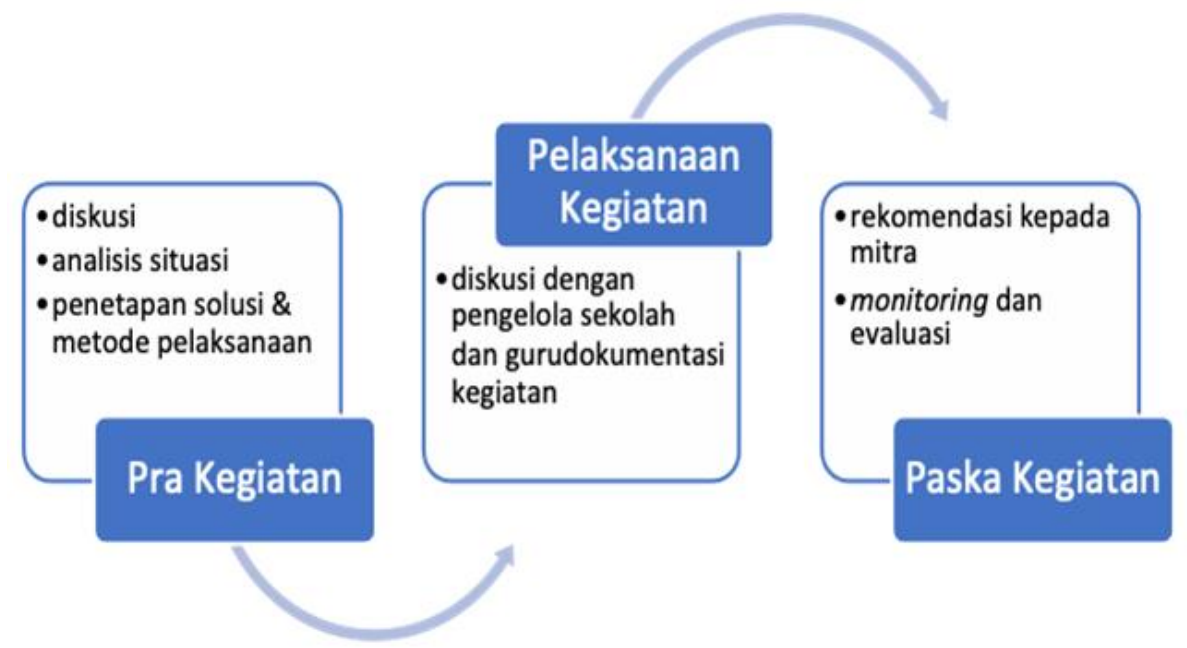

Gambar 1: Proses PKM di Sekolah Lia Stephanie

Sumber: Tim Pelaksana 


\section{HASIL DAN PEMBAHASAN}

Penelitian ini dibagi menjadi tiga bagian yaitu; Pra kegiatan yang akan membahas tentang masalah-masalah komunikasi yang dihadapi sekolah tersebut dalam pelayanan dari sisi pengelola. Kedua, terkait pelaksanaan kegiatan yang akan membahas tentang Komunikasi dan Budaya Organisasi dalam Membangun Citra Sekolah di Tengah Masyarakat. Ketiga, adalah evaluasi kegiatan.

\section{Pra kegiatan}

Beberapa waktu yang lalu pada tanggal 15 Agustus 2019, Fakultas Ilmu Komunikasi Universitas Tarumanagara dikunjungi oleh perwakilan Human Resource Development (HRD) Andri dari Yayasan Lia Stephanie. Kunjungan tersebut membahas tentang rencana mengundang pihak Fakultas Ilmu Komunikasi Universitas Tarumanagara untuk memberikan pelatihan kepada pengelola sekolah di Lia Stephanie. Menurut (HRD) Yayasan Lia Stephanie masih terdapat permasalahan komunikasi yang muncul dalam proses pelayanan dan pembelajaran. Oleh sebab itu Yayasan Lia Stephanie merasa tepat memohon bantuan pakar Ilmu Komunikasi di Universitas Tarumanagara dalam membantu memetakan, menganalisis, dan memberikan solusi atas apa yang mereka hadapi. Dari hasil kunjungan tersebut, disepakati bahwa Fakultas Ilmu Komunikasi Universitas Tarumanagara akan mengadakan workshop dengan tema "Komunikasi dan Budaya Organisasi dalam Membangun Citra Sekolah di Tengah Masyarakat". Pemilihan tema tersebut didasarkan kebutuhan Mitra.

\section{Pelaksanaan kegiatan}

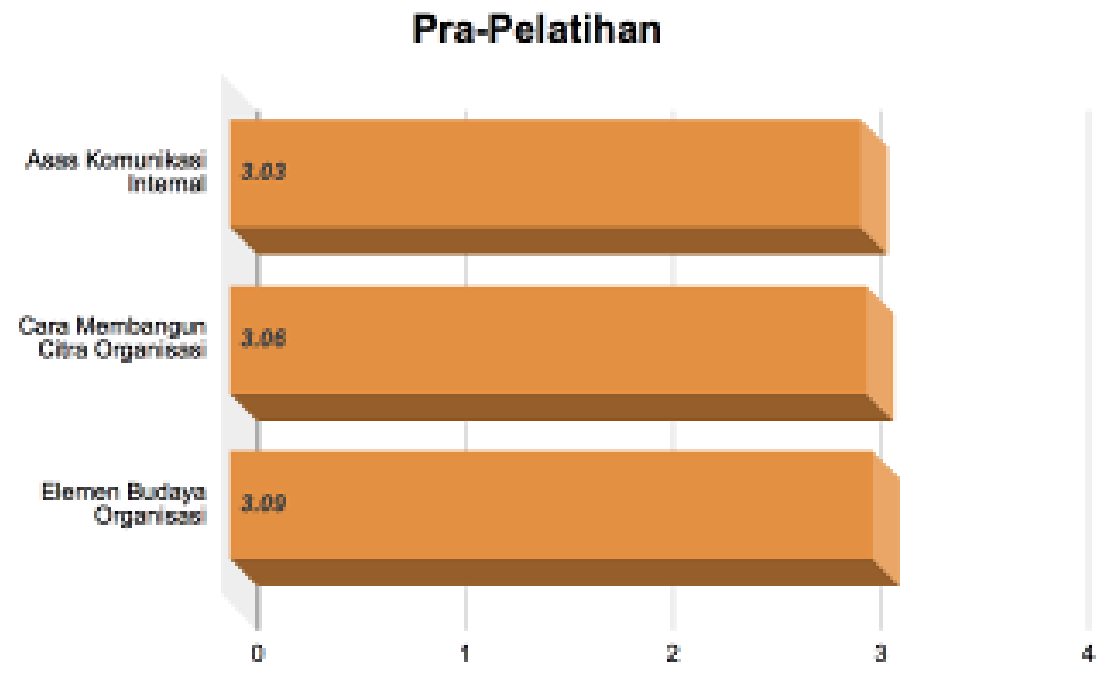

Gambar 2: Hasil Kuesioner Pra-Pelatihan

Sumber: (Dokumentasi Tim)

Workshop dilaksanakan pada 5 Oktober 2019 dan dihadiri oleh Human Resource Development (HRD) Yayasan Lia Stephanie dan guru-guru Sekolah Lia Stephanie. Di awal workshop tim PKM Fakultas Ilmu Komunikasi Universitas Tarumanagara memperkenalkan seluruh tim kepada seluruh peserta dengan tujuan untuk membangun komunikasi yang nyaman kepada seluruh peserta agar workshop berjalan dengan baik. Setelah berkenalan tim memulai workshop dengan terlebih dahulu menyebarkan kuesioner dengan tujuan ingin mengetahui pemahaman dasar peserta workshop terkait Komunikasi dan Budaya Organisasi sekolah. Kuesioner berisi tentang asas 
komunikasi internal, cara membangun citra organisasi, dan elemen budaya organisasi. Dari hasil kuesioner tersebut terlihat pemahaman peserta workshop terkait komunikasi internal berada pada angka 3.03. sedangkan dalam cara membangun citra organisasi berada pada 3.06. Selanjutnya terkait pemahaman elemen budaya organisasi berada pada angka 3.09. Hasil kuesioner prapelatihan dapat dilihat pada Gambar 2.

Setelah melaksanakan kuesioner Pra-Pelatihan, tim melanjutkan memberikan materi dengan tema Komunikasi dan Budaya Organisasi dalam Membangun Citra Sekolah di Tengah Masyarakat. Materi disampaikan oleh Dr. Riris Loisa yang membahas tentang Komunikasi dan Budaya Organisasi seperti yang dapat dilihat pada Gambar 3. Komunikasi adalah suatu proses sosial dimana individu menggunakan simbol untuk membangun dan menginterpretasikan makna dalam lingkungan mereka, melalui unsur komunikasi termediasi dengan peran teknologi dalam masyarakat kontemporer (Turner, 2017).

Pentingnya komunikasi dalam organisasi untuk membangun keselarasan dalam mencapai tujuantujuan organisasi membutuhkan empat point. Pertama, Sistem makna bersama di dalam suatu organisasi yang membedakannya dari organisasi lainnya, dan merupakan karakteristik kunci yang dijunjung tinggi oleh anggota-anggota organisasi, kedua, Nilai-nilai yang dianut dalam komunikasi organisasi harus dipahami bersama. Ketiga, cara kerja yang efisien dan inovatif harus selalu ditumbuhkan untuk memperkuat organisasi tersebut dalam berkompetisi. Terakhir adalah keyakinan, dengan keyakinan untuk meraih tujuan-tujuan organisasi dibutuhkan keyakinan yang kuat di seluruh lapisan organisasi.

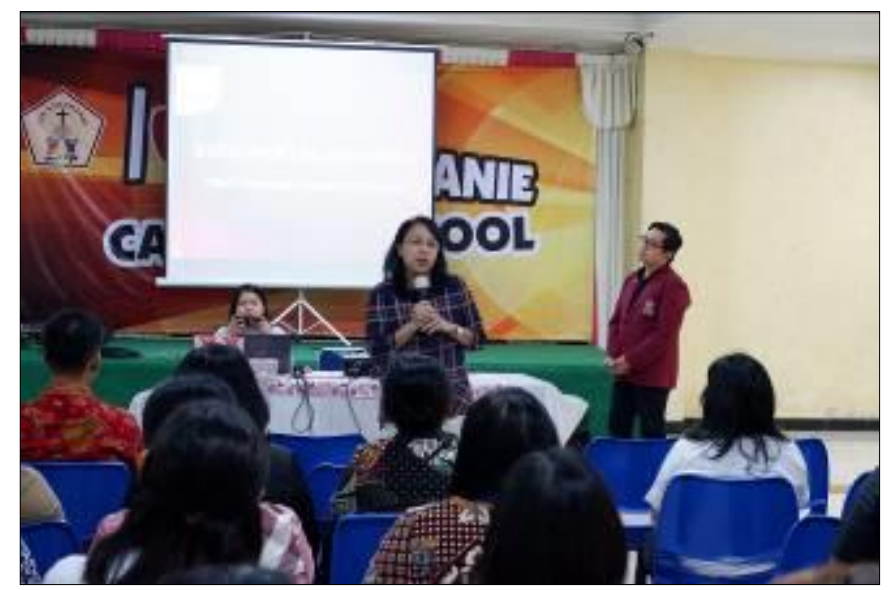

Gambar 3: Narasumber Dr. Riris Loisa, M.Si.

Sumber: (Dokumentasi Tim)

Materi selanjutnya dipresentasikan oleh Yugih Setyanto, S.Sos, M.Si. pada kegiatan itu narasumber memaparkan pentingnya mengelola citra bagi sekolah untuk melakukan pelayanan internal dan eksternal. Peran Humas dalam perusahaan diperlukan untuk mengatur arah strategi Public Relations yang tepat dalam merancang brand image dari perusahaan maupun produknya. Usaha tersebut dilakukan agar dapat menarik dan mendapatkan kepercayaan dari konsumen (Tamara \& Setyanto, 2018). Tidak hanya di perusahaan, sekolah sebagai sebuah organisasi juga harus tetap membangun brand image.

Dalam proses yang dilakukan dalam workshop tema Komunikasi dan Budaya Organisasi dalam Membangun Citra Sekolah di Tengah Masyarakat sebagai berikut:

1) Tim PKM Fikom Untar membagikan alat tulis dan note kepada peserta 
2) Peserta workshop diminta untuk menuliskan masalah yang dihadapi terkait proses pelayanan disekolah seperti pada Gambar 5.

3) Setelah itu peserta workshop akan menempelkan note di papan tulis

4) Tim Fikom Untar kemudian mulai membaca secara cepat masalah apa saja yang dihadapi guru-guru disekolah.

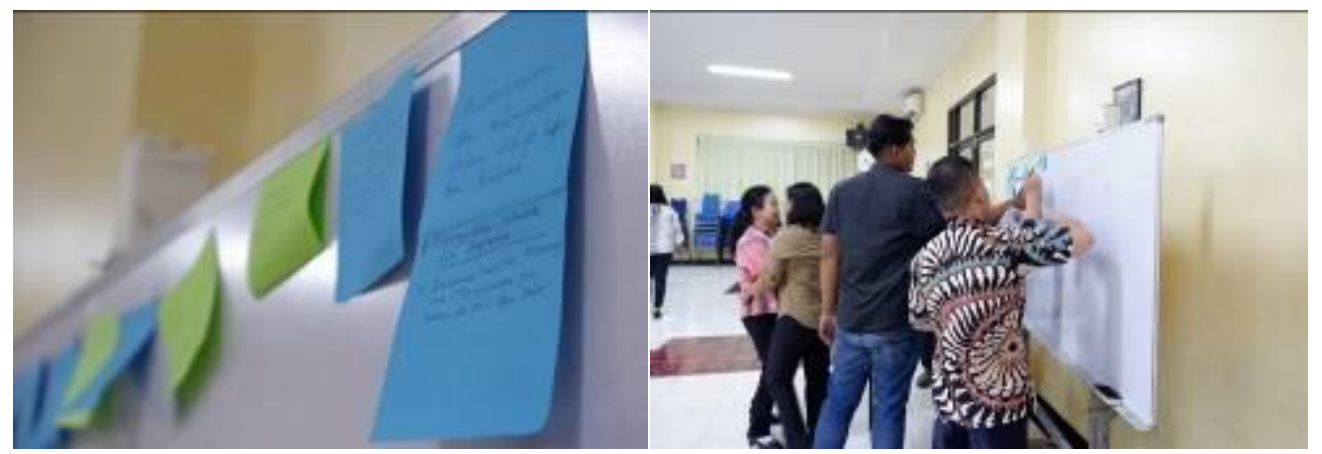

Gambar 5: Pemetaan Masalah

Sumber: (Dokumentasi Tim)

Di bawah ini adalah ringkasan dari keseluruhan permasalahan yang terjaring dari diskusi, sebagai berikut:

1) Peraturan dan sistem organisasi lebih di perjelas

2) Aturan harus tegas, berlaku untuk semua kalangan dan golongan (bukan Hanya kalangan tertentu)

3) Kesejahteraan karyawan dan guru karena guru dan karyawan adalah ujung tombak sekolah.

4) Manajemen organisasi sekolahnya: keputusan-keputusan terkait kegiatan sekolah ada di tangan Kepsek, bukan di koordinator sekolah.

Dari empat data di atas nampannya terdapat masalah komunikasi menurut perspektif guru-guru dalam hal ini adalah pelaksana dalam kegiatan pendidikan dan pelayanan disekolah. Masalah tersebut terlihat dari terhambatnya arus informasi dari atas ke bawah, begitu juga baliknya. Para guru menilai atasan dalam hal ini adalah Yayasan kurang berkomunikasi kepada pelaksanaan di Sekolah, sehingga membuat kebingungan dan kesalahpahaman antara guru. Perlu diketahui praktik komunikasi efektif dalam orga- nisasi diterapkan dalam kegiatan koordinasi antar unit dalam organisasi (Harivarman, 2017). Namun dalam prosesnya seringkai menemui hambatanhambatan komunikasi.

Hambatan tersebut tidak hanya terjadi disekolah, tetapi diberbagai level organisiasi. Seperti pada riset terkait hambatan komunikasi di dalam organisasi Kantor Pos Medan. Masalah yang diangkat dalam penelitian tersebut adalah hambatan pelaksanaan komunikasi organisasi vertikal ke atas pada sebuah Kantor Pos Medan (Sidauruk, 2013). Hambatan komunikasi tidak hanya terjadi dilevel organisasi, tetapi juga bisa terjadi pada masyarakat sosial. Seperti penelitian terkait hambatan komunikasi di Kota Pontianak yang terdiri dari mayoritas antar etnis kerukunan. konflik antar etnis dapat timbul disebabkan oleh tidak adanya keterbukaan dalam menghadapi perbedaan, selain itu masalah toleransi dan saling menghargai etnis, hambatan komunikasi juga menjadi salah satu faktor timbulnya konflik antar etnis tersebut (Paramita \& Carissa, 2018).

Setelah mengikuti workhsop peserta kembali diberikan kuesioner terkait pemahaman mereka terkait asas komunikasi internal, cara membangun citra organisasi, dan elemen budaya organisasi. 
Dari hasil kuesioner tersebut terlihat peningkatan pemahaman mereka terkait asas komunikasi internal berada pada angka 3.43. sedangkan dalam cara membangun citra organisasi berada pada 3.43. Selanjutnya terkait pemahaman elemen budaya organisasi berada pada angka 3.43. Hasil kuesioner pra-pelatihan dapat dilihat pada Gambar 6.

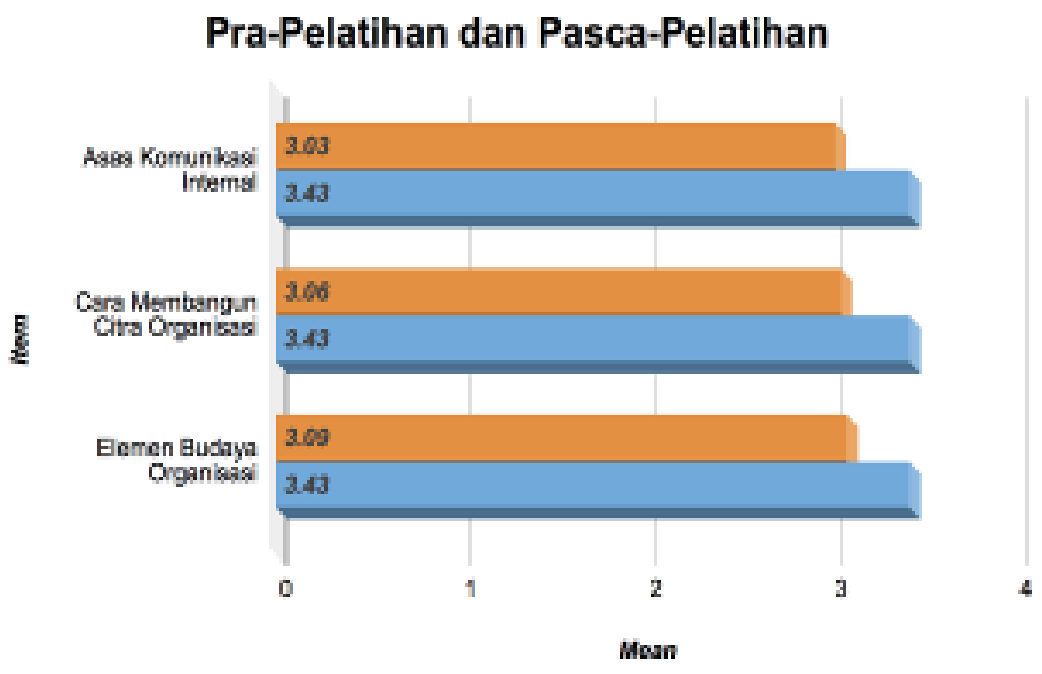

Gambar 6. Kuesioner hasil Pra Pelatihan dan Pasca - Pelatihan Sekolah Sekolah Lia Stephani Sumber: (Dokumentasi Tim)

Dari hasil kuesioner terdapat perubahan sebelum mengikuti workshop dan sesudah mengikuti workshop. Peserta worshop lebih memahami asas komunikasi internal, cara membangun citra organisasi, dan elemen budaya organisasi. Hasil tersebut menunjukkan bahwa workshop bisa dikatakan efektif berdasarkan gambar 8 di atas. Walaupun peserta workshop telah memahami terkait komunikasi dan budaya organisasi dalam membangun citra sekolah di tengah masyarakat. Namun demikian permasalahan yang terjadi dalam lingkup sekolah tersebut yaitu arus komunikasi dari atas ke bahwa yang harus diperbaiki. Sehingga komunikasi bisa berjalan baik semua kebijakan bisa dipahami maknanya sehingga organisasi bisa berjalan sesuai dengan tujuan organisasi.

\section{KESIMPULAN}

Masalah terkait iklim komunikasi organisasi khususnya di Sekolah masih menjadi persoalan yang serius di Indonesia. Dengan menciptakan suasana iklim komunikasi organisasi yang baik, pelayanan pendidikan seperti pembelajaran dan lain-lain dapat menciptakan citra dan reputasi bagi sekolah tersebut. Kesimpulan dari workshop Komunikasi dan Budaya Organisasi dalam Membangun Citra Sekolah di Tengah Masyarakat adalah peserta mengetahui terkait pemahaman terkait asas komunikasi internal, cara membangun citra organisasi, dan elemen budaya organisasi. Saran yang dapat diberikan dari hasil implementasi kegiatan Pengabdian Kepada Masyarakat (PKM) Fakultas Ilmu Komunikasi Universitas Tarumanagara adalah dapat menjadi masukan bagi pihak sekolah untuk mengetahui permasalahan yang terjadi di sekolah, selanjutnya dapat memperbaiki permasalahan komunikasi dan meningkatkan pelayanan pendidikan.

\section{Ucapan Terima Kasih}

Ucapan terima kasih diberikan kepada para peserta workshop, Sekolah Lia Stephani, Lembaga Penelitian dan Pengabdian Masyarakat Universitas Tarumanagara, Fakultas Ilmu Komunikasi dan Prodi Ilmu Komunikasi Universitas Tarumanagara 


\section{REFERENSI}

Harivarman, D. (2017). Hambatan Komunikasi Internal di Organisasi Pemerintahan. Jurnal ASPIKOM, 3(3), 508. https://doi.org/10.24329/aspikom.v3i3.171

Panuju, R., \& Narena, I. K. (2019). Jurnal komunikasi. Jurnal Komunikasi (Vol. 11). Retrieved from https://journal.untar.ac.id/index.php/komunikasi/article/view/2297/3144

Paramita, S., \& Carissa, M. R. (2018). Inter-Ethnic Communication Barriers in Pontianak City | Paramita | Jurnal The Messenger. Jurnal The Messenger, 10(1), 54-62. https://doi.org/10.26623/themessenger.v10i1.550

Sidauruk, P. L. (2013). Analysis of Vertical Communication Organization Barriers in. Jurnal Penelitian Pos Dan Informatika, 3(2), 133-164.

Tamara, J., \& Setyanto, Y. (2018). Strategi Public Relations dalam Membangun Brand Image Jamu (Studi pada Suwe Ora Jamu Kedai Jamu \& Kopi)|Tamara | Prologia. Retrieved December 1, 2019, from https://journal.untar.ac.id/index.php/prologia/article/view/3715/2155

Yayu, N., Anisti, A., Hidayat, D., \& Suhadi, M. (2019). Pendekatan intercultural communication pada public relations PT Santos dalam membangun komunikasi empati. PRofesi Humas, 4(1), 122. https://doi.org/10.24198/PRH.V4I1.18626 